\title{
KELAS IBU HAMIL DAN PERILAKU PERAWATAN BAYI
}

\author{
Sri Mulyati, Fauzia Djamilus \\ Poltekkes Kemenkes Bandung, Jl. Dr. Sumeru no 116 Bogor \\ e-mail: chinata98@yahoo.co.id
}

\section{MATERNAL CLASS AND INFANT CARE BEHAVIOR}

\begin{abstract}
Neonatal period is a critical period in life because adaptation to life in the womb transition to life outside the womb. The study aims to determine the relationship of the mother's participation in classes pregnant mother to infant care behavior. The study population throughout post partum mothers with infants aged up to 1 month in Bogor City Regional Health Center. Cross-sectional study design. The sample size is calculated using two different test sample of 43 respondents obtained proportion. By multistage sampling technique sampling. The statistical test used is chi square. The results showed the husband support related to infant care behavior. It is important to motivate health workers to be accompanied by the mother's immediate family at least once a mother classroom activities.
\end{abstract}

Keywords: maternal class, infant care, hypothermia

\begin{abstract}
Abstrak: masa neonatus merupakan masa kritis dalam kehidupan karena transisi adaptasi kehidupan dalam rahim ke kehidupan luar rahim. Penelitian bertujuan mengetahui hubungan keikutsertaan ibu pada Kelas Ibu hamil terhadap perilaku perawatan bayi. Populasi penelitian seluruh ibu post partum yang memiliki bayi usia hingga 1 bulan di Wilayah Puskesmas Kota Bogor. Desain penelitian Cross Sectional, sampel sebanyak 43 responden. Teknik penarikan sampel secara Multistage sampling. Uji statistik yang digunakan adalah chi square. Hasil penelitian menunjukkan dukungan suami berhubungan dengan perilaku perawatan bayi. Penting kiranya tenaga kesehatan memotivasi ibu untuk didampingi oleh keluarga terdekat minimal satu kali dalam kegiatan kelas ibu.
\end{abstract}

Kata Kunci: kelas ibu, perawatan bayi, hipotermi

\section{PENDAHULUAN}

Berkaitan dengan kelangsungan hidup bayi, Angka Kematian Bayi di Kota Bogor pada tahun 2013 mencapai 62 bayi dan pada tahun 2014 masih terdapat 57 kematian bayi yang terbanyak $45(79 \%)$ terjadi pada masa neonatus dengan rincian asfiksia 16, Bayi Berat Lahir Rendah (BBLR) 17, kelainan kongenital 8, sepsis 5 dan diare 1 bayi (Dinkes Kota Bogor, 2014).

Depkes RI (2009) menekankan pentingnya nasihat pada ibu oleh tenaga kesehatan dalam perawatan bayi baru lahir yang mencakup IMD, cara pemberian ASI eksklusif, cara menjaga kehangatan bayi, cara merawat tali pusat dan cara merangsang perkembangan bayi.

IMD (Inisiasi Menyusu Dini) dapat mengurangi $22 \%$ kematian bayi berusia 28 hari kebawah. Pada tahun 2002, WHO juga merekomendasikan pemberian ASI eksklusif selama 6 bulan karena dapat menurunkan angka kematian anak sebesar 13\%. Perawatan tali pusat pada bayi yang direkomendasikan WHO dan AAP (American Academy of Pediatrics) adalah perawatan tali pusat cara kering tanpa antiseptik ataupun antimikroba. Rerata lama puput tali pusat lebih cepat pada perawatan kering dibanding perawatan alkohol dan providon iodin (Yefri, dkk., 2010).

Menjaga kehangatan bayi sangat penting dilakukan untuk mencegah terjadinya hipotermia. Terjadinya hipotermia merupakan salah satu penyebab morbiditas dan mortalitas pada bayi terlebih pada Bayi Berat Lahir Rendah (BBLR) karena hipotermia mempengaruhi metabolisme tubuh dan dapat mengakibatkan komplikasi hipoglikemia, asidosis metabolik, distres pernafasan dan infeksi (Nelson, 2004). Hipotermi dapat terjadijika bayi diletakkan di ruangan yang 
suhunya lebih rendah dari suhu bayi, air ketuban di tubuh bayi yang tidak langsung dikeringkan, handuk basah yang tidak dipindahkan dari tubuh bayi, bayi baru lahir yang langsung dimandikan, serta ditundanya Inisiasi Menyusu Dini (IMD) (Wiknjosastro, 2008).

Hasil penelitian Wijayanti (2012) mengenai pengaruh kelas ibu hamil terhadap perilaku perawatan bayi baru lahir di Kota Metro menggunakan studi cohort retrospektif, menjelaskan pengetahuan tentang pencegahan hipotermi dan jumlah anggota keluarga berhubungan dengan pencegahan hipotermi. Dukungan tenaga kesehatan serta jumlah anggota keluarga berhubungan dengan perawatan tali pusat.

Hal yang sama juga diungkapkan oleh Haryanto dan Ella (2008) pada penelitiannya tentang determinan praktik ibu dalam merawat bayi baru lahir, dimana hanya sebagian ibu yang melakukan pencegahan hipotermia dengan benar seperti meletakkan bayi baru lahir di dada ibu, memakaikan topi pada kepala bayi serta sarung tangan dan kaki pada bayi baru lahir.

Insiden hipotermi dapat diturunkan setelah mendapatkan penyuluhan tentang persiapan mandi yang baik. Hasil penelitian Puspita, Suradi dan Munazir (2012) dari 50\% insiden hipotermi di puskesmas dan rumah bersalin swasta, setelah mendapatkan penyuluhan turun menjadi $37 \%$. Faktor risiko yang berkorelasi adalah suhu aksilla yang aman $37^{\circ} \mathrm{C}$ dan suhu air mandi $35^{\circ} \mathrm{C}$.

Adanya stimulus (rangsang) yang berasal dari lingkungan dapat diterima atau ditolak oleh organisme. Sikap akan terbentuk bila ada reinforcing dari lingkungan yang kemudian akan menimbulkan efek pada tindakan (perilaku) seseorang. Teori ini mengungkapkan betapa pentingnya reinforcing dalam hal ini dukungan keluarga dan tenaga kesehatan dalam perawatan bayi (Notoatmodjo, 2010).

Suami mempunyai tanggungjawab yang penuh dalam suatu keluarga dan suami mempunyai peranan penting tidak hanya sebagai pencari nafkah akan tetapi sebagai pemberi motivasi atau dukungan dalam kebijakan yang akan diputuskan termasuk merencanakan keluarga, dalam hal ini termasuk perawatan pada bayinya.

Salah satu program pemerintah untuk menurunkan angka kesakitan dan kematian dalam masa kehamilan, persalinan, nifas dan bayi baru lahir adalah dengan penggunaan buku KIA. Penyebarluasan buku KIA bertujuan agar terjadi peningkatan pengetahuan dan keterampilan petugas kesehatan serta adanya peningkatan kualitas pelayanan. Selain itu buku KIA juga sebagai alat pemantau kesehatan Ibu dan Anak, wahana pendidikan dan penyuluhan bagi masyarakat (Kemenkes RI, 2011).

Upaya yang bisa dilakukan untuk memudahkan ibu hamil memahami isi buku KIA dan bagaimana cara menggunakannya diantaranya melalui penyelenggaraan kelas ibu hamil. Materi perawatan BBL pada peserta kelas ibu hamil diajarkan pada pertemuan kedua dan ketiga kelompok kelas ibu hamil. Tujuan perawatan bayi pada pertemuan kelas ibu hamil yaitu ibu mengetahui tanda bayi lahir sehat dan sakit, hal yang harus dilakukan pada bayi baru lahir serta memahami tanda bahaya bayi baru lahir (Depkes RI, 2009).

Hasil penelitian Syafiq dkk, (2008) mengenai dampak kelas ibu hamil untuk persiapan persalinan terhadap pengetahuan, sikap dan perilaku dalam kehamilan, persalinan dan masa pasca kelahiran di Lombok Tengah NTB, menyebutkan bahwa semua ibu di desa intervensi KIH menyatakan memperoleh pengetahuan, skill tentang kehamilan, persalinan sebaga manfaat dari KIH. Pengetahuan, sikap dan perilaku ibu yang mengikuti KIH lebih baik daripada yang tidak mengikuti KIH. Hasil penelitian yang dilakukan oleh Wijayanti (2012) yang menjelaskan bahwa dukungan tenaga kesehatan 
yang diterima responden yang ikut KIH tidak sama dengan yang tidak ikut KIH.

Terjadinya hipotermia merupakan salah satu penyebab morbiditas dan mortalitas pada bayi terutama BBLR karena hipotermia mempengaruhi metabolisme tubuh dan dapat mengakibatkan komplikasi hipoglikemia, asidosis metabolik, distres pernafasan dan infeksi. Setelah dilakukan intervensi kelas ibu hingga kini belum terdata perilaku ibu post partum dalammelakukan perawatan bayi. Oleh karena itu tujuan penelitian ini untuk mengetahui karakteristik dan hubungan keikutsertaan ibu dalam kelas ibu hamil dengan perilaku perawatan bayi baru lahir.

\section{METODE PENELITIAN}

Penelitian ini adalah penelitian analitik yang menjelaskan pola kausalitas atau fungsi sebab akibat dari variabel independent terhadap variabel dependent. Penelitian merupakan penelitian kuantitatif dengan pendekatan potong lintang (cross sectional) dilaksanakan di Kota Bogor pada bulan Februari s.d Agustus 2015.

Sumber data adalah data primer yang diperoleh dari hasil wawancara dan observasi. Populasi penelitian yaitu seluruh ibu post partum di wilayah Dinas Kesehatan Bogor yang memiliki bayi hingga usia 1 bulan. Sampel penelitian adalah ibu nifas sebanyak 45 orang dihitung menggunakan rumus uji beda dua proporsi. Teknik pengambilan sampel secara Multistage random sampling kepada 6 kecamatan yang ada di Kota Bogor, terpilih 3 puskesmas yang ada di wilayah 6 kecamatan tersebut. Jumlah sampel dari tiap-tiap puskesmas proporsional. Pengambilan sampel dari tiap-tiap puskesmas dilakukan dengan teknik simple random sampling. Kriteria inklusi adalah ibu post partum yang menetap di Wilayah Puskesmas Kota Bogor dan memiliki bayi usia hingga 1 bulan, bayi dalam kondisi sehat.
Data diperoleh dengan observasi dan wawancara langsung kepada responden dengan cara melakukan kunjungan rumah. observasi tindakan/perilaku dilakukan pada saat ibu melakukan perawatan bayi khususnya dalam mencegah hipotermi. Instrumen yang digunakan pada saat observasi adalah checklist.

Analisa data univariat dilakukan dengan menghitung nilai proporsi pada masing-masing kategori. Analisis bivariat dilakukan dengan menguji hubungan antara keikutsertaan ibu di kelas ibu dengan perilaku dalam perawatan bayi dengan uji chi square. Kemudian dilakukan pula uji chi square terhadap keikutsertaan ibu di kelas ibu dengan dukungan suami dan dukungan tenaga kesehatan sebagai variabel confounding.

\section{HASIL PENELITIAN}

Pada Tabel 1 Karakteristik responden dari aspek pendidikan, 29 orang $(64,4 \%)$ responden berpendidikan SLTA dan sarjana sebanyak 2 orang $(4,4 \%)$. Karakteristik responden bila ditinjau dari aspek usia, responden berada pada usia 17 hingga 43 dan rata-rata berusia 27.56 tahun. Terdapat $33.3 \%$ responden berusia resiko untuk kehamilan yaitu < 20 tahun dan $>30$ tahun. Responden yang baru pertama kali melahirkan sebanyak 20 orang $(44,4 \%)$, sedangkan yang pernah melahirkan tiga kali sebanyak 8 orang $(17,8 \%)$.

Hasil pada Tabel 2 menunjukkan dari 45 responden yang ikut kelas ibu hamil sebanyak 23 orang $(51,1 \%)$, sedangkan yang tidak ikut kelas ibu hamil sebanyak 22 orang $(48,9 \%)$.

Berdasarkan Tabel 3 proporsi ibu yang mengikuti kelas ibu hamil sebesar 78,3 yang memiliki perilaku perawatan bayinya baik dan ibu yang tidak mengikuti kelas ibu hamil berperilaku baik dalam merawat bayinya sebesar $63,6 \%$. Keadaan ini hampir seimbang, artinya tidak ditemukan hubungan yang bermakna variabel keikusertaan ibu pada kelas hamil terhadap 
perilaku perawatan bayi.

Pada variabel confounder dukungan tenaga kesehatan diperoleh hasil tidak ada hubungan antara kedua variabel. Akan tetapi pada variabel dukungan suami terjadiperbedaan proporsi yaitu ibu yang mendapatkan dukungan suami memiliki proporsi sebesar $87 \%$ yang merawat bayinya baik sedangkan ibu yang kurang memiliki dukungan suami memiliki proporsi $54,5 \%$. Diperoleh nilai OR sebesar 5,556 dan $p$ value $=0,016$ dengan demikian ada hubungan yang bermakna antara dukungan suami dengan perilaku perawatan bayi. Dukungan suami memberikan pengaruh sebesar 5,6 kali untuk merawat bayinya dibandingkan ibu yang kurang mendapatkan dukungan.

\section{PEMBAHASAN}

Hasil penelitian menunjukkan, dari 45 responden, sebanyak $66,7 \%$ berada pada usia reproduktif dan hanya $2,2 \%$ yang berusia muda. Usia paling muda 17 tahun dan paling tua 43 tahun. 64,4 berpendidikan SLTA dan 4,4 berpendidikan sarjana. Sebanyak $44 \%$ dari responden adalah ibu yang baru pertama kali melahirkan dan 17,8\% memiliki anak tiga. Usia mempengaruhi kedewasaan seseorang dalam berfikir karena mengacu pada pengalaman yang dimilikinya. Semakin muda usia semakin sedikit pengalaman dalam persalinan (Dedeh, 2009 dalam Qurmiasih.N dan Hani. U,. 2014) demikian pula tentunya pengalaman ibu dalam merawat bayi. Hasil penelitian lain dikemukakan oleh Lucia.S., dkk (2015) bahwa terjadi peningkatan pengetahuan tentang persiapan persalinan pada 36 responden yang $42 \%$ berpendidikan SMAdan pada ibu yang multipara. Melalui pendidikan akan membuka wawasan dan mudah menerima perubahan. Pengalaman yang dimilikioleh ibu dalam merawat bayi sebelumnya dijadikan acuan dalam merawat bayinya saat ini.
Ibu yang mengikuti kelas ibu hamil dan yang tidak mengikuti hampir seimbang (Tabel2). Hasil penelitian di Kota Bogor yang dilakukan oleh Handayani, dkk (2008) terdapat pengaruh antenatal class terhadap pemilihan penolong persalinan, data yang diperoleh dari $37 \%$ ibu hamil yang merencanakan persalinan di paraji setelah dilakukan intervensi dengan mengikuti kelas ibu hamil, yang bersalin di paraji sebanyak $13 \%$.

Hasil penelitian ini pada Tabel 3 menunjukkan responden yang tidak ikut kelas ibu hamil 36,4\% kurang baik dalam merawat bayi sedangkan responden yang mengikuti kelas ibu hamil 21,7\% yang kurang baik dalam merawat bayi. Hasil uji bivariat diperoleh nilai $0,279 \mathrm{OR}=2,05795 \% \mathrm{CI}$ $(0,551-7,683)$ artinya tidak ada hubungan yang bermakna responden yang tidak ikut kelas ibu hamil dibandingkan dengan yang ikut kelas ibu hamil.

Berbeda dengan penelitian ini adalah penelitian yang dilakukan oleh Wijayanti (2012) yang menyatakan keikutsertaan ibu dalam kelas ibu hamil memberikan pengaruh positif pada perilaku ibu dalam merawat bayi baru lahir. Ibu yang mengikuti kelas ibu hamil berpeluang melakukan pencegahan hiotermia dengan baik lebih besar 4,78 kali dibandingkan dengan ibu yang tidak ikut KIH. ${ }^{7}$ Menurut Effendy dalam Rohani tahun 2013 Keterampilan identik dengan pendidikan kesehatan karena keduanya berorientasi kepada perubahan perilaku yang diharapkan yaitu perilaku sehat. Responden yang diberikan penyuluhan demonstrasi akan memberikan perubahan peningkatan pengetahuan khususnya keterampilan dalam memberikan perawatan bagi bayinya secara benar.

Terdapat 3 faktor yang memiliki kontribusi terhadap perubahan perilaku kesehatan seseorang, yaitu preferensi pribadi yang dibawa seseorang atau kelompok, faktor antesenden terhadap perilaku yang memungkinkan motivasi 
atau inspirasi terlaksana serta faktor penguat yang memungkinkan adanya manfaat sosial dan manfaat fisik serta ganjaran nyata atau tidak nyata yang pernah diterima pihak lain. Ternyata keikutsertaan ibu pada kelas ibu hamil bukan merupakan satu-satunya faktor yang mempengaruhi perilaku responden dalam merawat bayi (Green, et al., 1980).

Di masyarakat peran petugas kesehatan adalah sebagai role model, teladan dan juga sebagai acuan perilaku hidup sehat. Informasi yang diberikan oleh petugas kesehatan sangat mempengaruhi tingkat pengetahuan ibu yang pada akhirnya akan mempengaruhi perilakunya. Pengetahuan merupakan faktor predisposisi terjadinya perilaku dan dukungan tenaga kesehatan merupakan salah satu penguat perubahan perilaku seseorang (Green, et al. 2005).

Hasil analisis menunjukkan responden yang tidak memiliki dukungan tenaga kesehatan $68 \%$ dalam melakukan perawatan bayi kurang sedangkan yang memiliki dukungan dalam melakukan perawatan bayi kurang sebanyak $73,9 \%$. Hasil uji bavariat didapatkan pvalue $=0,672 \mathrm{OR}=1,32295 \% \mathrm{CI}(0,363$ $4,816)$ artinya tidak ada hubungan yang bermakna responden yang memiliki dukungan dari tenaga kesehatan dibandingkan dengan yang tidak memiliki dukungan dalam melakukan perawatan bayi. Hasil penelitian ini sejalan dengan dengan hasil penelitian Haryanto (2008) mengenai determinan praktik ibu dalam perawatan neonatal di garut yang menyebutkan bahwa dukungan dan penyuluhan yang diberikan oleh petugas kesehatan tidak berhubungan dengan perilaku ibu dalam memberikan kolostrum maupun perawatan pada bayi baru lahir.

Dukungan suami akan memberikan kekuatan tersendiri bagi ibu. Dukungan tersebut dapat dilakukan dengan cara membantu istri dalam merawat bayinya. Faktor budaya seringkali membatasi wanita untuk mengambil keputusan bagi perawatan diri dan anggota keluarganya dalam hal ini anak-anaknya. Pada kehidupan rumah tangga, wanita tidak lepas dari perannya sebagai ibu. Seharusnya lebih banyak perhatian yang diberikan pada wanita terkait dengan perannya dalam merawat dan mendidik anakanaknya. Tingkat pendidikan suami juga memengaruhi wawasan dan pengetahuannya termasuk dalam merawat bayi. Semakin rendah pengetahuan suami maka akses terhadap informasi kesehatan bagi anggota keluarganya juga akan berkurang sehngga suami akan kesulitan mengambil keputusan secara efektif (Jayanta, P.H, 2013).

Hasil analisis hubungan dukungsn suami dengan perilaku ibu dalam merawat bayinya menunjukkan sebanyak 20 responden $(87 \%)$ yang mendapatkan dukungan suami dalam merawat bayi melakukan perawatan dengan baik ada bayinya. Sebagian kecil yaitu 12 responden $(54,5 \%)$ dari responden yang kurang mendapat dukungan suami melakukan perawatan bayi dengan baik.

Uji statistik menunjukkan ada perbedaan yang signifikan antara dukungan suami dengan perawatan bayi ( $\mathrm{p}$ value $=0,016$ dengan $\mathrm{OR}=$ 5,556 95\% CI (1,270-24,293) Artinya ada hubungan yang bermakna suami yang mendukung dibandingkan dengan yang tidak mendukung dalam merawat bayi. Ibu yang mendapatkan dukungan suami berpeluang 5,56 kali merawat bayinya dengan baik dibandingkan ibu yang tidak mendapatkan dukungan.

Suami mempunyai tanggungjawab yang penuh dalam suatu keluarga dan suami mempunyai peranan penting tidak hanya sebagai pencari nafkah akan tetapi sebagai pemberi motivasi atau dukungan dalam kebijakan yang akan diputuskan termasuk merencanakan keluarga, dalam hal ini termasuk perawatan pada 
bayinya. Sejalan dengan penelitian yang dilakukan oleh Wijayanti (2012) yang menyatakan ada hubungan yang bermakna antara dukungan suami dalam pencegahan hipotermia dengan perilaku ibu dalam mencegah hipotermia. Hal ini sesuai dengan teori Green and Kreuter (2005) yang menyebutkan dukungan suami merupakan salah satu faktor penguat perubahan perilaku seseorang atau sekelompok orang yang memungkinkan adanya imbalan atau penghargaan terhadap perubahan perilaku yang menetap dan berulang.

\section{PENUTUP}

Sebanyak 23 responden $(51.1 \%)$ mendapat dukungan tenaga kesehatan dalam perawatan bayi baru lahir. Terutama pada aspek Menyelimuti bayi menggunakan selimut, Melakukan teknik menyusui dengan benar, Mengecek suhu air mandi, Segera mengeringkan setelah mandi, Memakaikan topi ke kepala bayi, Memakaikan sarung kaki. Tidak terdapat hubungan yang bermakna antara keikutsertaan pada kelas ibu hamil demikian pula dukungan tenaga kesehatan dengan perilaku perawatan bayi. Namun terdapat hubungan yang bermakna antara dukungan suami dengan perilaku perawatan bayi.

Berdasarkan hasil penelitian ini, maka kami memberikan saran kepada bidan di puskesmas sebagai berikut: 1) Perlu kiranya bidan di puskesmas mengajak dan memotivasi ibu agar aktif menghadiri kegiatan kelas ibu hamil, sehingga pengetahuan dan keterampilan ibu merawat bayi meningkat, 2) Sangat penting dilakukan sosialisasi yang komprehensif mengenai kelas ibu hamil, 3) Akan lebih baik lagi bila bidan berusaha menghadirkan suami minimal satu kali pada saat kegiatan kelas ibu hamil, agar ibu memiliki motivasi yang lebih kuat dan mendapat dukungan dari suami.

\section{DAFTAR PUSTAKA}

Alam, M,A, et al. 2006. Newborn Umbilical Cord and Skin Care in Sylhet District, Bangladesh: Implications for the promotion of umbilical cord cleansing with topical chlorhexidine. Journal of Perinatology,28.

Bimo, W. 2004. Pengantar Psikologi Umum. Yogyakarta: Andi Offset

Depkes, RI. 2008. Acuan Persalinan Normal. Jalarta

Depkes RI. 2009. Pegangan Fasilitator Kelas Ibu Hamil. Jakarta

Dinas Kesehatan Kota Bogor. 2014. Profil Kesehatan Kota Bogor 2014

Green, Kreuter, Deeds and Partridge. 1980. Health Educational Planning A Diagnosis Approach. Mayfield Publishing Company : California

Green, L.W, \& Kreuter, M,W. 2005. Health Program Planning and Educational and Ecological Approach, (4th ed). The Mc Graw-Hill Companies : New York

Handayani, dkk. (2008). Efektifitas Antenatal Class Terhadap Peningkatan Pengetahuan (Kehamilan, Persalinan, Perawatan Nifas) Dan Dampaknya Terhadap Pemilihan Tenaga Penolong Persalinan Di Wilayah Puskesmas Kota Bogor. Poltekkes Kemenkes Bandung: Perwakilan Jurusan Kebidanan Bogor

Haryanto, A dan Ella, N.H. 2008. Praktik Ibu dalam Perawatan Neonatus di Kabupaten Garut. [Tesis]. FKM UI : Depok

Jayanta, P.H. 2013. Hubungan Dukungan Suami dengan Sikap Ibu dalam Pemberian ASI Eksklusif di Wilayah Kerja Puskesmas Arjasa Kabupaten Jember, [Skripsi] : Universitas Jember. 
Joseph Mizzi and Ruth Vella Muskat. 2007. Hypothermia in the Early Neonatal Period : Follow up Study, St Luke's Hospital, Malta : Malta Medical Journal. Vol.19, issue 01. Tersedia darihttp://www.um.edu.mt/ umms/mmj/PDF/166.pdf

Kemenkes, RI. Buku saku Pelayanan Kesehatan Neonatal Esensial. 2011. Diunduh tanggal 4 Desember 2014. Tersedia dari: http://www.gizikia.depkes. go.id/wp-content/uploads/downloads/2011/ 09/Buku-Saku-Pelayanan-Kesehatan-Neonatal-Esensial.pdf.

Lucia.S., Purwandari.A dan Pesak.E. 2015. Pengaruh Pelaksanaan Kelas Ibu Hamil Terhadap Pengetahuan Tentang Persiapan Persalinan. Jurusan Jurnal Ilmiah Bidan, vol 3 No 1-Juni 2015.

Nelson. 2004. Ilmu Kesehatan Anak

Nila.Q dan Ummu. H. 2014. Hubungan Aktivitas Kelas Ibu Hamil Terhadap Kesiapan Menghadapi Persalinan di Puskesmas Gedongtengen Yogyakarta. Skripsi : Stikes Aisyiyah Yogyakarta

Notoatmodjo, S. 2010. Ilmu Perilaku. Rineka Cipta : Jakarta

Nurhidayanti,A. 2009. Hubungan Pelaksanaan IMD dengan Kejadian Hipotermi di RSUD Jend A. Yani Metro. Karya Tulis Ilmiah : Prodi Kebidanan Metro Poltekkes Kemenkes Tanjungkarang

Puspita,dkk. 2007. Insiden dan Faktor Risiko Hipotermia Akibat Memandikan pada Bayi Baru Lahir Cukup Bulan. Sari Pediatri. Vol.8, No.4. Jurnal Ikatan Dokter anak Indonesia [Online], Tersedia dari http:/ /www.idai.or.id . 4 Maret 2007
Rohani, S. 2013. Faktor-Faktor yang Mempengaruhi Pengetahuan dan Keterampilan dalam Perawatan Bayi di Ruang Nifas RSUD Lanto DG Pasewang Kab. Jeneponto, Makassar. Jurnal Stikes Nani Hasanuddin Makassar.Vol.3, No.5

Suryani, P. 2012. Pelaksanaan Inisiasi Menyusu Dini Pada Ibu Bersalin yang Ditolong Oleh Tenaga Kesehatan di Kota Bogor [Tesis] Universitas Indonesia Fakutas Kesehatan Masyarakat : Depok

Syafiq, A.,dkk. 2008. Laporan Penelitian Dampak Kelas Ibu Hamil Untuk Persiapan Persalinan Terhadap Pengetahuan, Sikap Dan Perilaku Dalam Kehamilan, Persalinan Dan Masa Pasca Kelahiran di Lombok Tengah NTB. Pusat Kajian Gizi dan Kesehatan FKM-UI) : Depok

Wahyuni, S. 2013. Pengalaman Ibu dalam Melakukan Perawatan Metode Kanguru. Jurnal Stikes Nani Hasanuddin Makassar.Vol.1, No.3

Wijayanti,Y,T. 2012. Pengaruh Kelas Ibu Hamil Terhadap Perilaku dalam Perawatan bayi di Kota Metro. [Tesis] Universitas Indonesia: Depok

Wiknjosastro, dkk. 2008. Ilmu Kebidanan. EGC : Jakarta

Yefri,dkk. 2010. Kolonisasi Kuman dan Kejadian Omfalitis pada Tiga Regimen Perawatan Tali Pusat pada Bayi Baru Lahir.Sari Pediatri. Vol.11, No.5. 5 Februari 2010 Jurnal Ikatan Dokter anak Indonesia [Online], dari http://www.idai.or.id diunduh tanggal 4 Desember 2014. 